\title{
Effect of Jig Design and Assessment of Stress Distribution in Testing Metal-Ceramic Adhesion.
}

Özcan, Mutlu ; Kojima, Alberto Noriyuki ; Nishioka, Renato Sussumu ; Mesquita, Alfredo Mikail Melo ; Bottino, Marco Antonio ; Filho, Gilberto Duarte

\begin{abstract}
PURPOSE In testing adhesion using shear bond test, a combination of shear and tensile forces occur at the interface, resulting in complex stresses. The jig designs used for this kind of test show variations in published studies, complicating direct comparison between studies. This study evaluated the effect of different jig designs on metal-ceramic bond strength and assessed the stress distribution at the interface using finite element analysis (FEA). MATERIALS AND METHODS Metal-ceramic (Metal: Ni-Cr, Wiron 99, Bego; Ceramic: Vita Omega 900, Vita) specimens $(\mathrm{N}=36)$ (diameter: $4 \mathrm{~mm}$, veneer thickness: $4 \mathrm{~mm}$; base diameter: $5 \mathrm{~mm}$, thickness: $1 \mathrm{~mm})$ were fabricated and randomly divided into three groups ( $\mathrm{n}=12$ per group) to be tested using one of the following jig designs: (a) chisel (CH) (ISO 11405), (b) steel strip (SS), (c) piston (PI). Metal-ceramic interfaces were loaded under shear until debonding in a universal testing machine $(0.5 \mathrm{~mm} / \mathrm{min})$. Failure types were evaluated using scanning electron microscopy (SEM). FEA was used to study the stress distribution using different jigs. Metalceramic bond strength data $(\mathrm{MPa})$ were analyzed using ANOVA and Tukey's tests $(\alpha=0.05)$. RESULTS The jig type significantly affected the bond results $(\mathrm{p}=0.0001)$. PI type of jig presented the highest results $(\mathrm{MPa})$ $(\mathrm{p}<0.05)(58.2 \pm 14.8)$, followed by $\mathrm{CH}(38.7 \pm 7.6)$ and SS jig type $(23.3 \pm 4.2)(\mathrm{p}<0.05)$. Failure types were exclusively a combination of cohesive failure in the opaque ceramic and adhesive interface failure. FEA analysis indicated that the SS jig presented slightly more stress formation than with the $\mathrm{CH}$ jig. The PI jig presented small stress concentration with more homogeneous force distribution compared to the $\mathrm{CH}$ jig where the stress concentrated in the area where the force was applied. CONCLUSION Metal-ceramic bond strength was affected by the jig design. Accordingly, the results of in vitro studies on metal-ceramic adhesion should be evaluated with caution. CLINICAL SIGNIFICANCE When adhesion of ceramic materials to metals is evaluated in in vitro studies, it should be noted that the loading jig type affects the results. Clinical observations should report on the location and type of ceramic fractures in metal-ceramic reconstructions so that the most relevant test method can be identified.
\end{abstract}

DOI: https://doi.org/10.1111/jopr.12378

Posted at the Zurich Open Repository and Archive, University of Zurich ZORA URL: https://doi.org/10.5167/uzh-127836

Journal Article

Accepted Version

Originally published at:

Òzcan, Mutlu; Kojima, Alberto Noriyuki; Nishioka, Renato Sussumu; Mesquita, Alfredo Mikail Melo; Bottino, Marco Antonio; Filho, Gilberto Duarte (2016). Effect of Jig Design and Assessment of Stress Distribution in Testing Metal-Ceramic Adhesion. Journal of Prosthodontics, 25(8):665-669.

DOI: https://doi.org/10.1111/jopr.12378 


\section{Category of manuscript: Short Communication}

\section{Effect of Jig Design and Assessment of Stress Distribution in Testing Metal-Ceramic Adhesion}

Mutlu Özcan, DDS, DMD, PhD, ${ }^{1}$ Alberto Noriyuki Kojima, DDS, PhD, ${ }^{2}$ Renato Sussumu Nishioka, DDS, $\mathrm{PhD},{ }^{3}$ Alfredo Mikail Melo Mesquita, DDS, PhD, ${ }^{3}$ Marco Antonio Bottino DDS, $\mathrm{PhD},{ }^{2}$ Gilberto Duarte Filho, DDS, $\mathrm{PhD}^{2}$

${ }^{1}$ University of Zurich, Dental Materials Unit, Center for Dental and Oral Medicine, Clinic for Fixed and Removable Prosthodontics and Dental Materials Science, Zurich, Switzerland

${ }^{2}$ Department of Dental Materials and Prosthodontics, São Paulo State University at São Jose dos Campos, Brazil

${ }^{3}$ Department of Prosthodontics, Paulista University at São Paulo, Brazil

Part of this study has been presented at the 84th General Session and Exhibition of the International Association for Dental Research (IADR), June 28 - July 1, 2006, Brisbane, Australia.

Short title: Effect of testing conditions on metal-ceramic adhesion

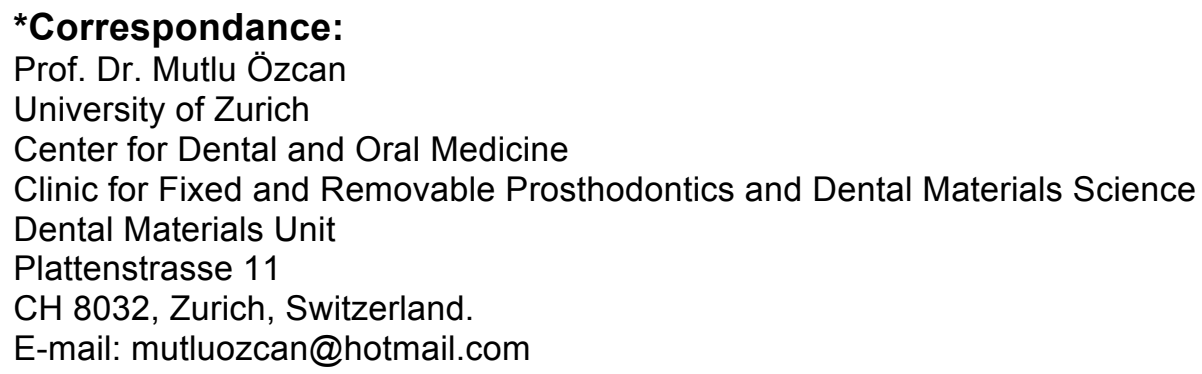




\section{Abstract}

Purpose: In testing metal-ceramic adhesion using shear bond test, a combination of shear and tensile forces occur at the interface resulting in complex stresses. The jig designs used for this kind of test show variations in the published studies that complicate the direct comparison between different studies. This study evaluated the effect of different jig designs on metal-ceramic bond strength and assessed the stress distribution at the interface using finite element analysis.

Materials and Methods: Metal-ceramic (Metal: Ni-Cr, Wiron 99, Bego; Ceramic: Vita Omega 900, Vita) specimens $(\mathrm{N}=36)$ (diameter: $4 \mathrm{~mm}$, veneer thickness: $4 \mathrm{~mm}$; base diameter: $5 \mathrm{~mm}$ and thickness: $1 \mathrm{~mm}$ ) were fabricated and randomly divided into three groups ( $n=12$ per group) to be tested using one of the following jig designs: a) chisel (CH) (ISO 11405), b) steel strip (SS), c) piston (PI). Metal-ceramic interfaces were loaded under shear until debonding in a Universal Testing Machine $(0.5 \mathrm{~mm} / \mathrm{min})$. Failure types were evaluated using Scanning Electron Microscopy (SEM). Finite element analysis (FEA) was used to study the stress distribution using different jigs. Metal-ceramic bond strength data (MPa) were analyzed using ANOVA and Tukey`s tests $(\alpha=0.05)$.

Results: The jig type significantly affected the bond results $(p=0.0001)$. PI type of jig presented the highest results $(\mathrm{MPa})(\mathrm{p}<0.05)(58.2 \pm 14.8)$ followed by $\mathrm{CH}(38.7 \pm 7.6)$ and SS jig type $(23.3 \pm 4.2)(p<$ 0.05). Failure types were exclusively a combination of cohesive failure in the opaque ceramic and adhesive interface failure. FEA analysis indicated that SS jig presented slightly more stress formation than with $\mathrm{CH}$ jig. PI jig presented small stress concentration with more homogeneous force distribution compared to $\mathrm{CH}$ jig where the stress concentrated in the area where the force was applied.

Conclusion: Metal-ceramic bond strength was affected by the jig design. Accordingly, the results of in vitro studies on metal-ceramic adhesion should be evaluated with caution.

Clinical Significance: When adhesion of ceramic materials to metals is evaluated in in vitro studies, it should be noted that the loading jig type affects the results. Clinical observations should report on the 
location and type of ceramic fractures in metal-ceramic reconstructions so that the most relevant test method could be identified.

Keywords Adhesion; Bond testing; Dental porcelain; Finite element analysis; Shear bond test. 


\section{Introduction}

Clinically, one of the main problems in metal-ceramic fixed dental prosthesis (FDP) is related to the adhesion between the ceramic veneer and the metallic frameworks leading to fracture of the ceramics with or without metal exposure. ${ }^{1-4}$ The quality of the metal-ceramic restoration union is frequently verified by different laboratory tests such as flexural, tensile and shear tests. ${ }^{3,5-9}$ The results of such studies may not be directly extrapolated to clinical situations but they could be considered as useful tools in establishing a clinical study protocol, previewing the effectiveness and behaviour of metal-ceramic combinations to be used. Moreover, the constant modifications in the material composition are another complication factor. Prior to a clinical study, in vitro studies help ranking performance of material combinations. Therefore, laboratory methods that take less time to be executed and permit evaluating the bond strength of metalceramic interfaces are important. In that respect, shear bond tests are the most popular in dental literature ${ }^{5-8,10-12}$ Forces are applied on a structure creates stresses that express how these forces are distributed in a given a structure. In that regard, forces that are applied laterally on the specimens create the complex stresses at the interface. Published studies use various jig designs that cause variations in the resulting values that complicate the direct comparison between different studies.

The objectives of this study therefore were to evaluate the effect of different jig designs on metal-ceramic bond strength and assess the stress distribution at the interface using finite element analysis. The null hypothesis tested was that jig type used for testing metal-ceramic shear bond would not affect the results significantly.

\section{Materials and Methods}

Standard (diameter: $4 \mathrm{~mm}$, veneer thickness: $4 \mathrm{~mm}$; base diameter: $5 \mathrm{~mm}$ and thickness: $1 \mathrm{~mm}$ ) wax patterns (Occlusal Wax Bego, Bremen, Germany) were prepared using a metallic matrix and cast in an induction machine (Ducatron, 3 series, Ugin Dentaire, France) using Ni-Cr alloy (Wiron 99, Bego). After casting, metal specimens were air-abraded with $110 \mu \mathrm{m} \mathrm{Al} \mathrm{O}_{3}$ (Korox, Bego) at 3 bar from a distance of 20 
$\mathrm{mm}$ at $45^{\circ}$ for 10 seconds. They were then ultrasonically cleaned in distilled water (Vitasonic II, Vita, Bad Säckingen, Germany) for 10 minutes and dried. The ceramic was applied on the air-abraded surfaces of the cast specimens.

Two layers of opaque ceramic (Vita Omega 900 Opaque) were applied in a controlled manner as described elsewhere ${ }^{13}$ and fired in a ceramic oven (Vacumat 40, Vita). Subsequently, dentin ceramic (Vita Omega 900 Dentin, Vita) was applied and fired in two steps to minimize the shrinkage according to manufacturer's instructions. No glaze ceramic was applied on the specimen surfaces. After firing the ceramic, the quality of the interface and the external form of the specimens were visually ensured that there is a smooth junction. If defects were noted, new specimens were fabricated. All specimens were then seated in the jig to verify their adaptation.

The specimens $(\mathrm{N}=36)$ (diameter: $4 \mathrm{~mm}$, veneer thickness: $4 \mathrm{~mm}$ ) were randomly divided into three groups ( $n=12$ per group) to be tested using one of the following jig design: a) chisel (CH) (ISO 11405), ${ }^{14} \mathbf{b}$ ) steel strip (SS), c) piston (PI) (Figs. 1a-c).

Metal-ceramic interfaces were loaded under shear until debonding in a Universal Testing Machine (EMIC, Model DL 1000, São José dos Pinhais, Brazil) with a load cell of $500 \mathrm{~kg}$ at a cross-head speed of 0.5 $\mathrm{mm} / \mathrm{min}$.

Failure types were evaluated using Scanning Electron Microscopy (SEM) (JSM-5500, Jeol, Tokyo, Japan).

Finite element analysis (FEA) was used to study the von Mises stress distribution under different loading conditions. For FEA, material properties were considered linear. A geometric model was built (IDEAS, UGSPLM Solutions, Plano, TX, USA) considering the specimen dimensions.

For material properties, the following were considered for FEA analysis: elasticity modulus of Ni-Cr: 205 GPa, Poisson's coefficient: 0.33 , elastic modulus of ceramic: 68.9 GPa, Poisson's coefficient: 0.28 . The 
manufacturers provided these data. The loading was performed, simulating the conditions to which the specimens were submitted, using the three jigs. The 3-D FEA were constructed with 1884 nodes and 1570 elements, and a load force of $600 \mathrm{~N}$ was used to make the analysis. The loading was performed replicating the laboratory conditions of this study. The blade was set to a point, contacting the ceramic and propagating at the bonding interface. While for the SS, it was considered that the strip surrounded the ceramic 180 degrees, for $\mathrm{PI}$, load was applied to the ceramic including its margins.

Metal-ceramic bond strength data (MPa) were analyzed using ANOVA and Tukey`s tests $(\alpha=0.05)$.

\section{Results}

Metal-ceramic bond strength was significantly affected when tested with different jig types $(p=0.0001)$. PI type of jig presented the highest results $(\mathrm{MPa})(\mathrm{p}<0.05)$ followed by $\mathrm{CH}$ and SS jig type $(p<0.05)($ Fig. 2).

Failure types were exclusively a combination of cohesive failure in the opaque ceramic and adhesive interface failure. In the $\mathrm{CH}$ (Figs. 3a-c) failure occurred initially in the ceramic, at the contact area with the chisel but ceramic remnants were less in the PI. When SS jig was used, larger quantity of ceramic remained on the metal in the form of a half-moon fracture (Figs. 3d-f). With the $\mathrm{PI}$, failure consistently initiated from the opaque ceramic-metal interface with extensive areas of metal indicating adhesive failure at the opaque ceramic-metal interface (Figs. 3h-i).

FEA analysis indicated greater stress concentration in a small area when shear bond strength test was performed by $\mathrm{CH}$ jig compared to other groups, followed by SS and PI (Figs. 4a-c). PI jig presented small stress concentration with more homogeneous force distribution at both compressive and tensile zones (Fig. 4c) compared to $\mathrm{CH}$ jig where the stress concentrated in the area where the force was applied only (Fig. 4a). 


\section{Discussion}

Since different jig designs used to test metal-ceramic bond strength showed significant differences, the null hypothesis could be rejected. There is inconsistency in measuring the bond strength of the veneering ceramics to coping substrates and an effort for its standardization is needed. While Lombardo et al. ${ }^{9}$ recommends a cross-head speed between 0.45 and $1.05 \mathrm{~mm} / \mathrm{min}$ for the shear bond strength test, Hara et al. ${ }^{15}$ recommended 0.5 to $0.75 \mathrm{~mm} / \mathrm{min}$. Tests performed at elevated cross-head speed could generate unfavourable distribution of the stresses, resulting in cohesive failures in the ceramic that may not allow measuring the real adhesion at the interface. In this study, in order to be able to make comparisons with previous studies, cross-head speed above $1 \mathrm{~mm} / \mathrm{min}$ was not practiced at the interface.$^{15} \mathrm{In}$ fact, during mastication displacement rates can easily exceed this value. ${ }^{15}$ Thus, future studies should correlate the findings metal-ceramic adhesion tests with the clinical observations especially in failure cases. Nevertheless, the mean bond strength results of the present study from the PI group $(58.2 \pm 14.8)$ were slightly less $(61.3 \pm 8.4 \mathrm{MPa})$ than that of Vasquez et al. ${ }^{13}$ where the same jig type and ceramic were used but in combination with Au-Pd alloy. The difference could be attributed to lower elastic modulus of AuPd versus $\mathrm{NiCr}$ where the latter possibly allowed for less deflexion and thereby, debonding of the ceramic at a lower magnitude of force.

The variation coefficients found in the current study were of approximately 18 to $25 \%(\mathrm{CH}$ : 19.69; SS: 18.06; PI: 25.51), which is pursuant to the ISO standard that indicates a coefficient with a variation less than $50 \%$. In general, the variation coefficients of the shear bond tests vary from 20 to $60 \%{ }^{1}$

FEA analysis indicated higher stress concentration with the $\mathrm{CH}$ jig followed by SS where the latter should be considered a better test in terms of stress distribution when compared to $\mathrm{CH}$. Among all jig types, SS and PI presented a more homogeneous stress distribution. Most probably the loading jig produced no fulcrum on the ceramic cylinder and thereby, no superficial deflection. In this case, the tensile and compression forces produced perpendicularly at the interface were smaller than the ones obtained in $\mathrm{CH}$ systems. 
With the $\mathrm{CH}$ jig, the knife blade may create shear and bending and thus the stress distribution at the interface is not the presumed shear bond strength. At this point, the ceramic was fractured and the cleavage propagation reached the interface, forming tension and compression, finally causing the deflection. In addition, it is almost impossible to achieve homogenous forces at the interface that is in fact also the clinical situation in the majority of the cases.

The lowest results were obtained with the SS jig indicating that the highest stresses occurred at the interface increases as the distance between the loading application point and the bond surface also increases; this is explained by the deformation of the stainless steel strip after tests. ${ }^{16-18}$

Considering that the failure types commonly observed clinically are between metal and the opaque layer, it can be stated that all jig types tested, despite the variations in the measured bond strength values, demonstrated clinically relevant failure types. ${ }^{4}$

\section{Conclusions}

1. When adhesion of veneering ceramic to $\mathrm{NiCr}$ is tested, shear bond strength tested by piston type of jig presented the highest shear bond strength followed by chisel.

2. Finite element analysis demonstrated that piston jig and steel strip presented less stress concentration with more homogeneous force distribution compared to chisel type.

3. Failure types were exclusively a combination of cohesive failure in the opaque ceramic and adhesive failure between the metal and opaque ceramic indicating the weakest link between the metal and the opaque ceramic. 


\section{References}

1. Wight TA, Bauman JC, Pelleu GB Jr: An evaluation of four variables affecting the bond strength of porcelain to nonprecious alloy. J Prosthet Dent 1977;37:570-577.

2. Daftary F, Donovan $\mathrm{T}$ : Effect of four pretreatment techniques on porcelain-to-metal bond strength. $\mathrm{J}$ Prosthet Dent 1986;56:535-539.

3. Craig RF, Powers J, Wataha JC: Dental Materials: Properties and Manipulation. 7. ed. São Paulo: Ed. Santos, 2002. p. 12-32.

4. Özcan M, Niedermeier W: Clinical study on the reasons for and location of failures of metal-ceramic restorations and survival of repairs. Int J Prosthodont 2002;15:299-302.

5. Anusavice KJ, Dehoff PH, Fairhurst CW: Comparative evaluation of ceramic-metal bond tests using finite element stress analysis. J Dent Res 1980;59:608-613.

6. Della Bona A, Van Noort R: Shear vs. tensile bond strength of resin composite bonded to ceramic. J Dent Res 1995;74:1591-1596.

7. Almilhatti HJ, Giampaolo ET, Vergani CE, et al: Shear bond strength of aesthetic materials bonded to Ni-Cr alloy. J Dent 2003;31:205-211.

8. Della Bona A, Anusavice $\mathrm{KJ}$, Mecholsky Jr JJ: Failure analysis of resin composite bonded to ceramic. Dent Mater 2003;19:693-699.

9. Lombardo GH, Nishioka RS, Souza RO, et al: Influence of surface treatment on the shear bond strength of ceramics fused to cobalt-chromium. J Prosthodont 2010;19:103-111.

10. Drummond JL, Randolph RG, Jekkals VJ, et al: Shear testing of the porcelain-metal bond. J Dent Res 1984;63:1400-1401.

11. Bondioli IR, Bottino MA: Evaluation of shear bond strength at the interface of two porcelains and pure titanium injected into the casting mold at three different temperatures. J Prosthet Dent 2004;91:541547. 
12. Melo RM, Travassos AC, Neisser MP: Shear bond strengths of a ceramic system to alternative metal alloys. J Prosthet Dent 2005;93:64-69.

13. Vásquez VZ, Özcan M, Kimpara ET: Evaluation of interface characterization and adhesion of glass ceramics to commercially pure titanium and gold alloy after thermal- and mechanical-loading. Dent Mater 2009;25:221-231.

14. International Standardization Organization (ISO) 11405: Tensile and adhesion shear fixtures for testing.

15. Hara AT, Pimenta LA, Rodrigues AL Jr.: Influence of cross-head speed on resin-dentin shear bond strength. Dent Mater 2001;17:165-169.

16. Carter JM, Al-Mudafar J, Sorensen SE: Adherence of a nickel-chromium alloy and porcelain. J Prosthet Dent 1979;41:167-172.

17. Chong MP, Beech DR: A simple shear test to evaluate the bond strength of ceramic fused to metal. Aust Dent J 1980;25:357-361.

18. Malhotra ML, Maickel LB: Shear bond strength in porcelain-metal restorations. J Prosthet Dent 1980;43:397-400. 


\section{Captions to tables and legends:}

\section{Figures:}

Figs. 1a-c The jig designs used for testing adhesion of veneering ceramic to metal a) chisel (CH) (ISO 11405) (blade thickness: $1 \mathrm{~mm}$ ), b) steel strip (SS) (width: $5 \mathrm{~mm}$, length: $1 \mathrm{~cm}$ ), c) piston (PI) allowing the placement of the metallic part of the specimen in the external part and the veneering ceramic in the internal part.

Fig. 2 Means and standard deviations of bond strength of veneering ceramic to metal using different types of jigs. a) Chisel (CH), b) Steel strip (SS), c) Piston (PI).

Figs. 3a-i a) Metal surface after debonding using $\mathrm{CH}$ where the presence of opaque ceramic at the margin could be observed (m: metal; c: ceramic), b-c) SEM images (x75 and x2200) from this group showing that the failure occurred in the ceramic located in the region where the chisel was applied, d) Metal surface after debonding using SS jig. Note that larger quantity of ceramic remained on the metal in the form of a half-moon fracture compared to other groups, e-f) SEM images (x33 and x1300) showing the cohesive fracture in the ceramic initiating from the margin, g) Metal surface after debonding using PI jig showing less ceramic remnants, $\mathbf{h}-\mathbf{i})$ SEM images (x75 and x1700) showing extensive areas of metal indicating adhesive interfacial failure. The principle load direction $(F)$ is indicated with an arrow in each image.

Figs. 4a-c FEA analysis of test simulation from lateral, front view of metal-ceramic assembly, transversa section of metallic base and ceramic surface when shear force was applied and tests were performed usinc different types of jigs. Note the highest stress concentration with the $\mathrm{CH}$ followed by SS and PI. Fol interpretation of the PI group, it should be noted that mathematical model was performed with perfect fit The symmetry of the loading pattern in the figures are unexpected as there should be some distortion as the loading occurs which could be due to the hole in the piston that does not have a precise fit to the specimen. The principle load direction $(F)$ is indicated with an arrow in each image. 


\section{Figures:}

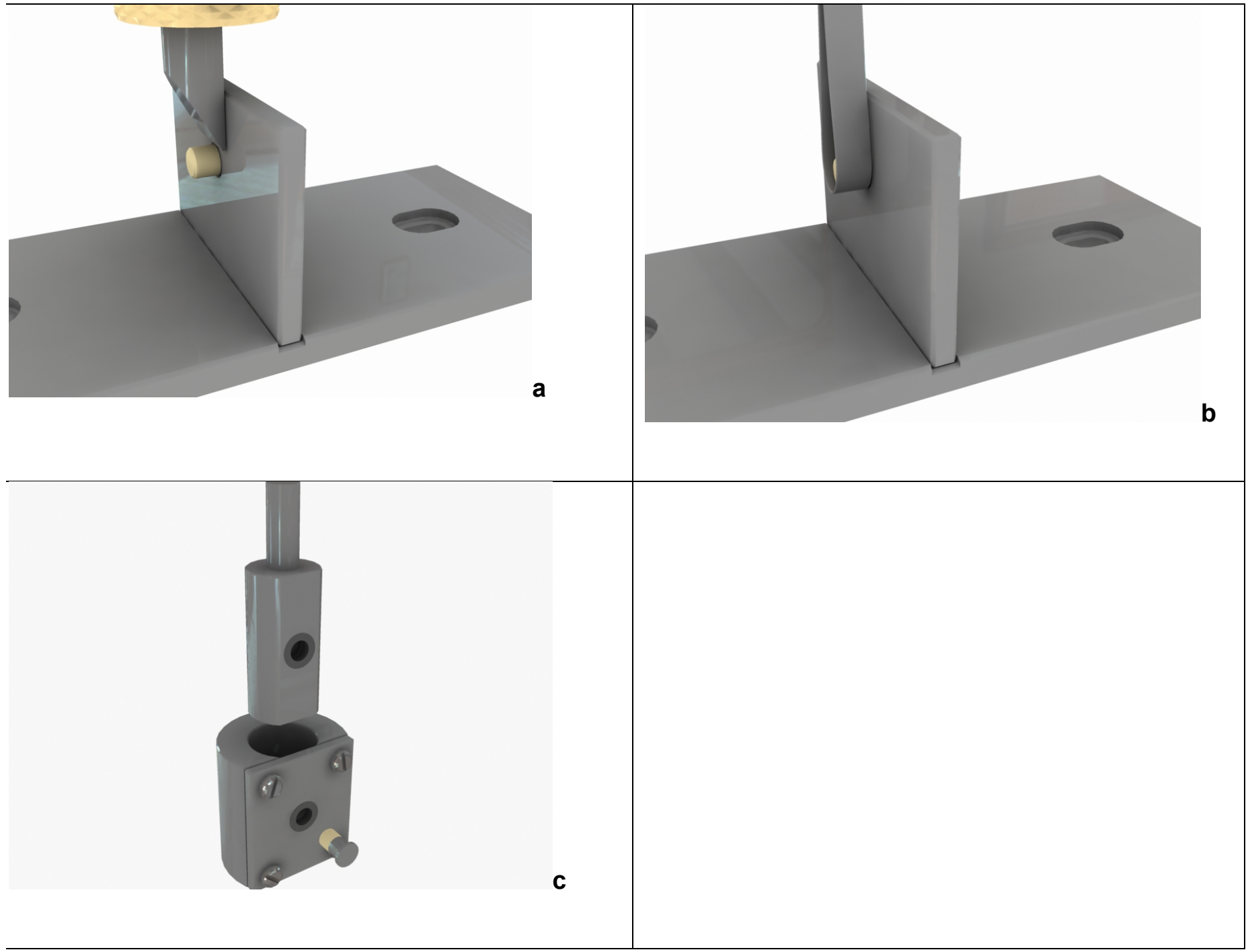

Figs. 1a-c The jig designs used for testing adhesion of veneering ceramic to metal a) chisel (CH) (ISO 11405) (blade thickness: $1 \mathrm{~mm}$ ), b) steel strip (SS) (width: $5 \mathrm{~mm}$, length: $1 \mathrm{~cm}$ ), c) piston (PI) allowing the placement of the metallic part of the specimen in the external part and the veneering ceramic in the internal part. 


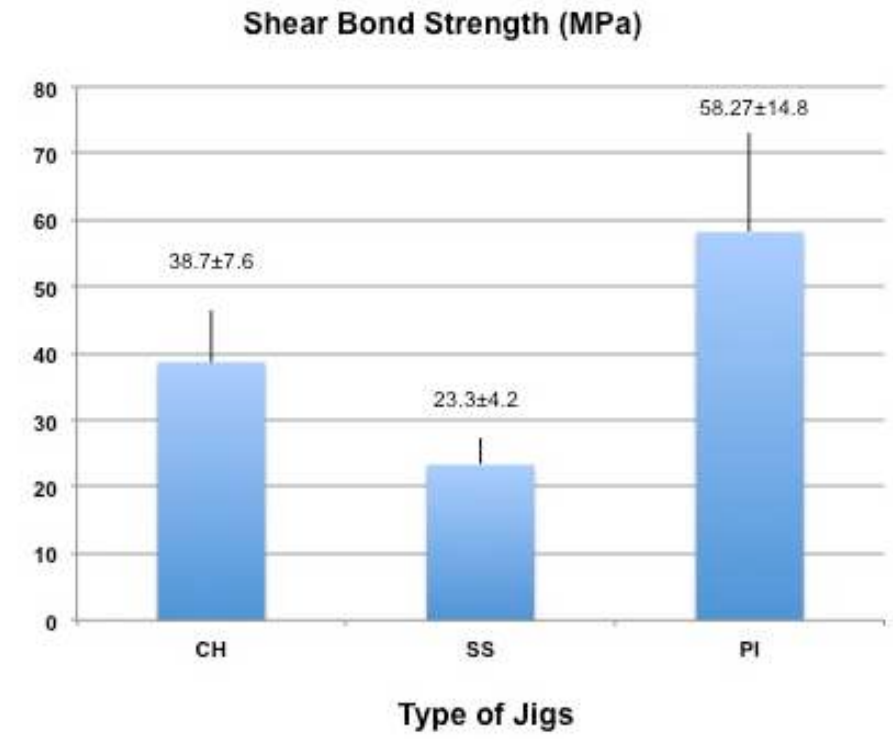

Fig. 2 Means and standard deviations of bond strength of veneering ceramic to metal using different types of jigs. a) Chisel (CH), b) Steel strip (SS), c) Piston (PI). 


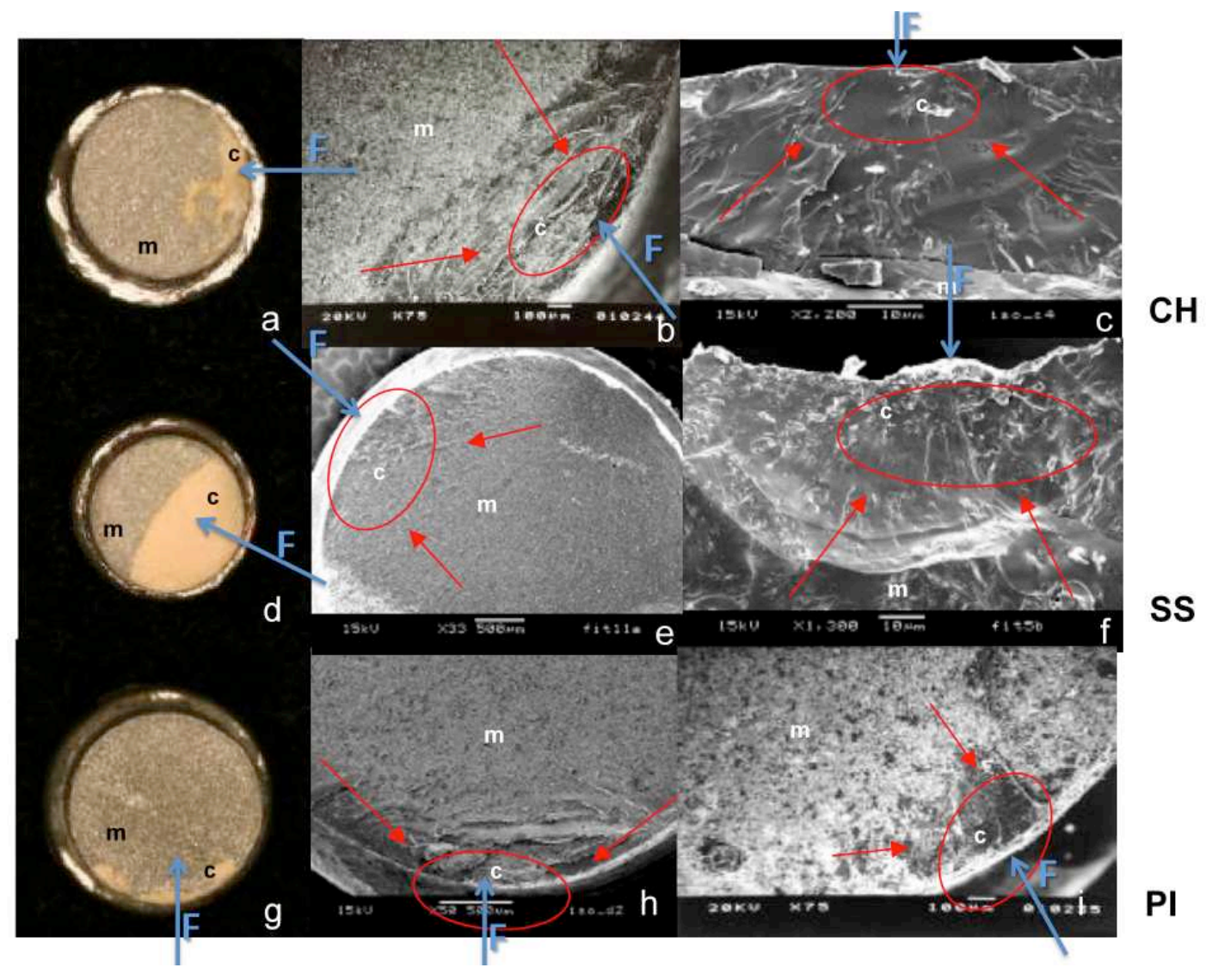

Figs. 3a-i a) Metal surface after debonding using $\mathrm{CH}$ where the presence of opaque ceramic at the margin could be observed (m: metal; c: ceramic), b-c) SEM images (x75 and x2200) from this group showing that the failure occurred in the ceramic located in the region where the chisel was applied, d) Metal surface after debonding using SS jig. Note that larger quantity of ceramic remained on the metal in the form of a half-moon fracture compared to other groups, e-f) SEM images (x33 and x1300) showing the cohesive fracture in the ceramic initiating from the margin, $\mathbf{g}$ ) Metal surface after debonding using PI jig showing less ceramic remnants, h-i) SEM images (x75 and x1700) showing extensive areas of metal indicating adhesive interfacial failure. The principle load direction $(F)$ is indicated with an arrow in each image. 

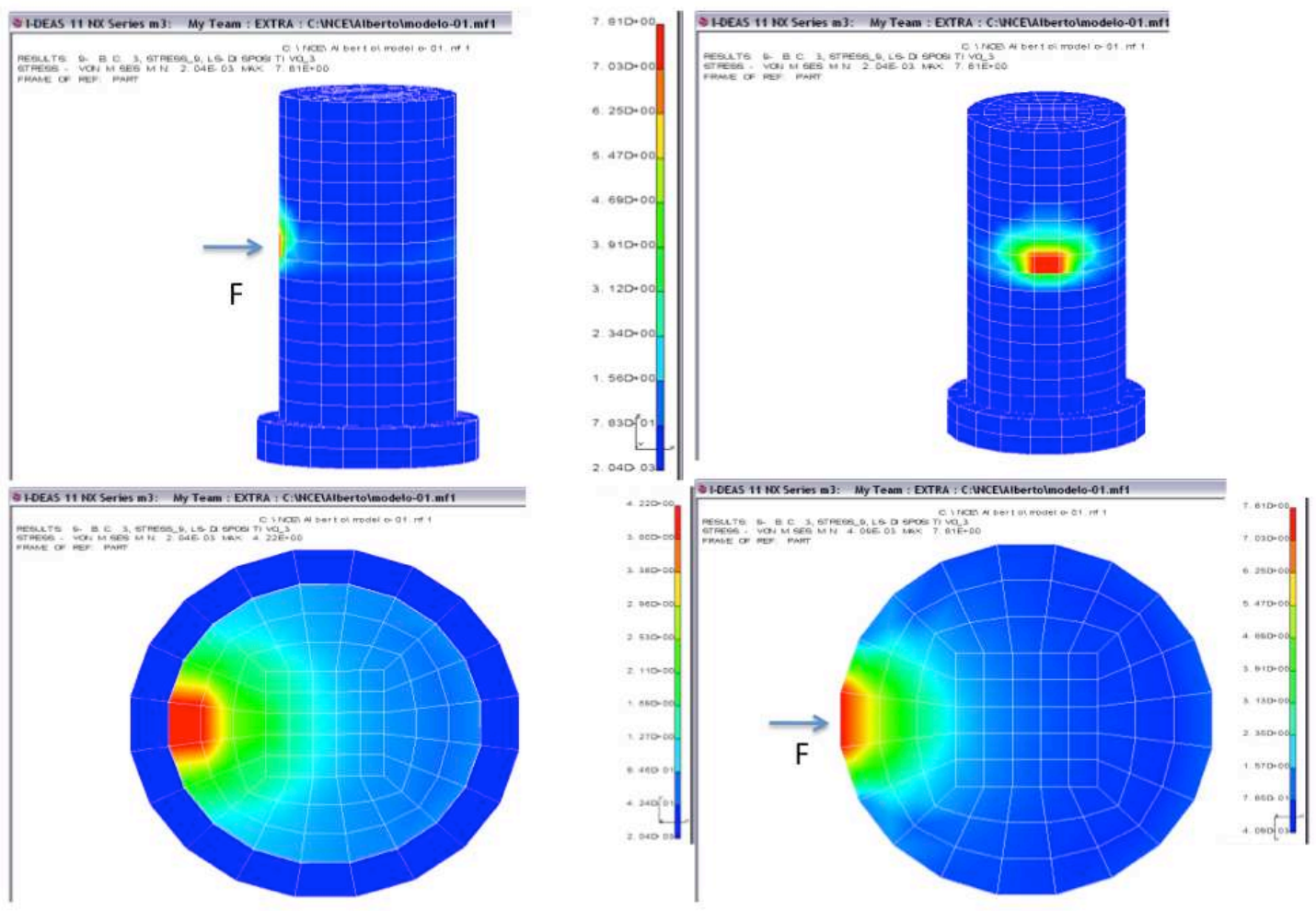

$\mathrm{CH}$ 

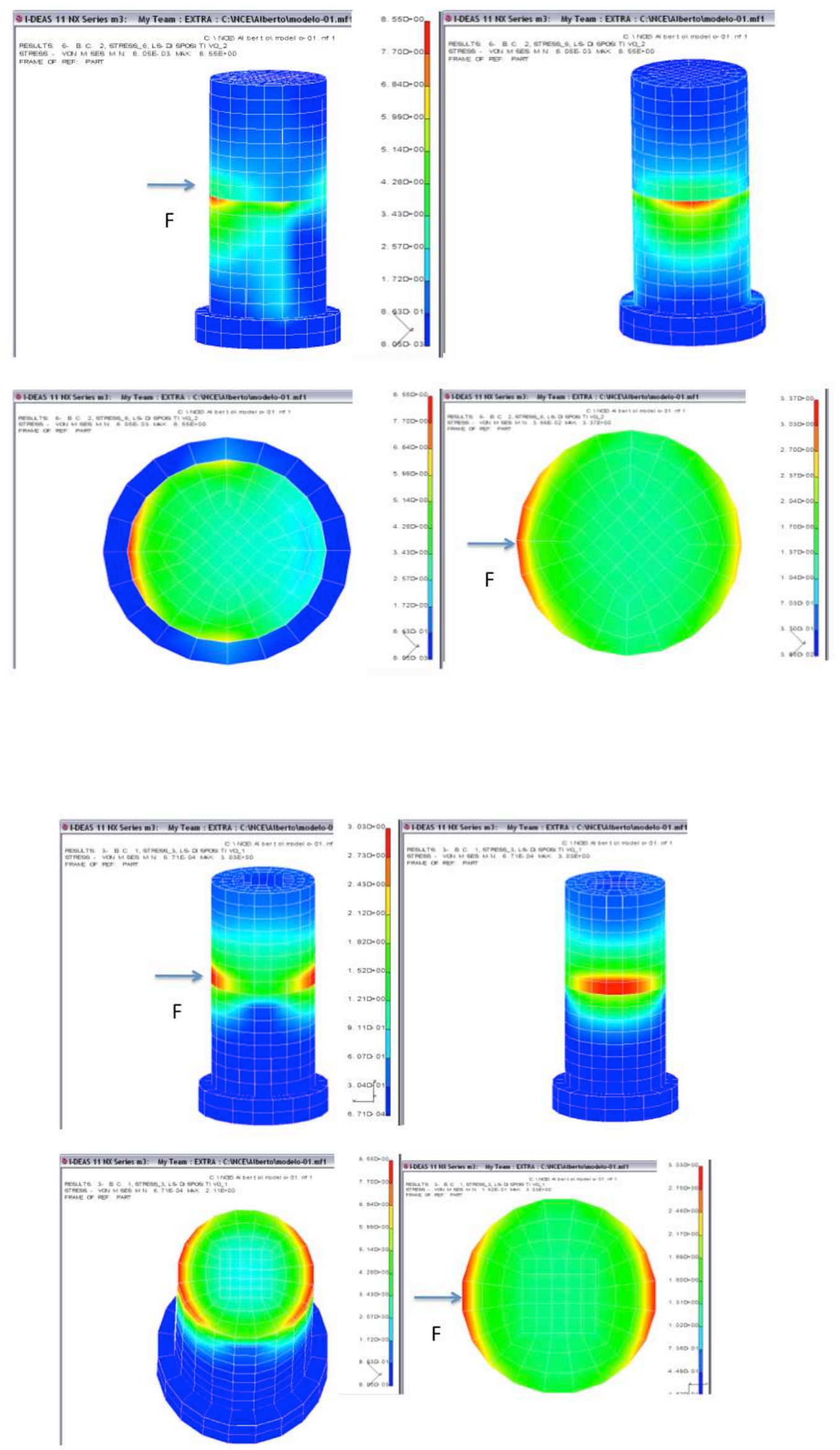
Figs. 4a-c FEA analysis of test simulation from lateral, front view of metal-ceramic assembly, transversal section o metallic base and ceramic surface when shear force was applied and tests were performed using different types 0 jigs. Note the highest stress concentration with the $\mathrm{CH}$ followed by $\mathrm{SS}$ and $\mathrm{PI}$. For interpretation of the $\mathrm{PI}$ group, $\mathrm{i}$ should be noted that mathematical model was performed with perfect fit. The symmetry of the loading pattern in th $\epsilon$ figures are unexpected as there should be some distortion as the loading occurs which could be due to the hole ir the piston that does not have a precise fit to the specimen. The principle load direction $(F)$ is indicated with an arron in each image. 